\title{
OBSERVATIONS OF THE NATURAL HISTORY AND ECOLOGY OF NEPENTHES CAMPANULATA
}

Charles Clarke $\bullet$ School of Science $・$ Monash University Sunway Campus • Jalan Lagoon Selatan

- Bandar Sunway•46150 Selangor Darul Ehsan•Malaysia・clarke.charles1@gmail.com CH’IEN C. LeE $\bullet 2507$ Peti Sura 93350 Kuching • Sarawak • Malaysia

VENO ENAR • Long Terawan • Tutoh • 98050 Baram • Sarawak • Malaysia

Keywords: Nepenthes campanulata, Borneo, Sarawak, limestone, prey, Palawan.

Abstract: Nepenthes campanulata is a little known species from limestone cliff habitats in Borneo. In this study, we conducted the first field-based survey of pitcher dimensions and the prey and invertebrate fauna in $N$. campanulata pitchers, sampled from plants growing on the cliff face above Deer Cave in Gunung Mulu National Park. We found that the dominant prey taxon is Diptera, followed by Formicidae. The metazoan community that inhabits the pitchers consists of just three species, making it one of the simplest in the genus. The pitchers of $N$. campanulata have a unique structure among Nepenthes, which may be related to the highly specialized habitat that the plant occurs in. Prior to this study, N. campanulata had been recorded at just two localities: Mt. Ilas Bungaan in East Kalimantan, and Gunung Mulu National Park in Sarawak. However, on a recent expedition to Palawan, we observed plants that we identified as $N$. campanulata, which represents a remarkable extension to the geographical range of this species.

\section{Introduction}

Nepenthes campanulata is one of the most unusual and poorly documented of all Nepenthes species. It is remarkable for the compact stature of the plant and its small, yellow, bellshaped pitchers, which give the plant its species name (Fig. 1). In terms of pitcher structure, the most similar species appears to be Nepenthes inermis from Sumatra, but these similarities are superficial - the upper pitchers of $N$. inermis lack a peristome entirely, and the inner surfaces are entirely glandular, lacking a layer of wax crystals. By contrast, the pitchers of $N$. campanulata have a minute, toothed peristome and a well-developed waxy zone that covers most of the inner surfaces of the pitchers. As we shall see below, the structure of $N$. campanulata

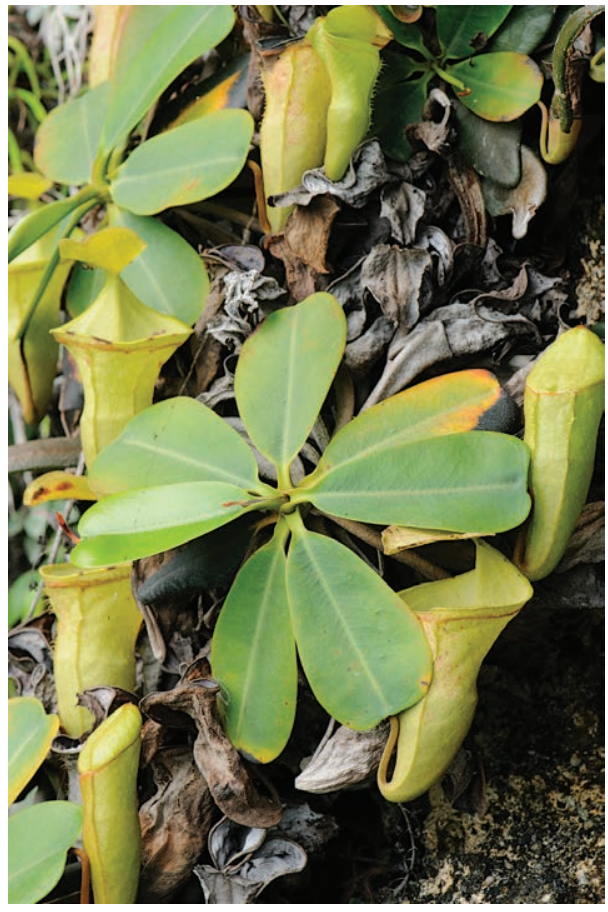

Figure 1: Close-up of a Nepenthes campanulata plant growing on a sheer limestone cliff face above Deer Cave, Gunung Mulu National Park, Sarawak. 
pitchers is in fact unique among Nepenthes, and the results of recent ecological research into the genus allows us to propose - for the first time how they might have evolved.

Nepenthes campanulata was first described by Kurata (1973). The description was based on a specimen collected in 1957 by A.J.G.H. Kostermans (Kostermans 13764, SIN) that was deposited at the Singapore Herbarium. The type locality was stated as "Mt Ilas Bungaan" in eastern Borneo. According to Kurata (1973), Kostermans trekked for 14 days to reach Mt. Ilas Bungaan, the face of which was said to be "completely overgrown with flowers". The "flowers" were in fact pitchers of $N$. campanulata. Until relatively recently, the precise location of Mt. Ilas Bungaan remained unknown to all but Kostermans. Eventually, the location was rediscovered, but recent visits to the type location (Mt. Ilas Bungaan) in eastern Borneo revealed that much of the vegetation on the mountain has been burned off, and no N. campanulata plants remained. As no other populations of $N$. campanulata were known at that time, it was thought that the species might be extinct.

In 1997, one of us (CL) discovered a popu-

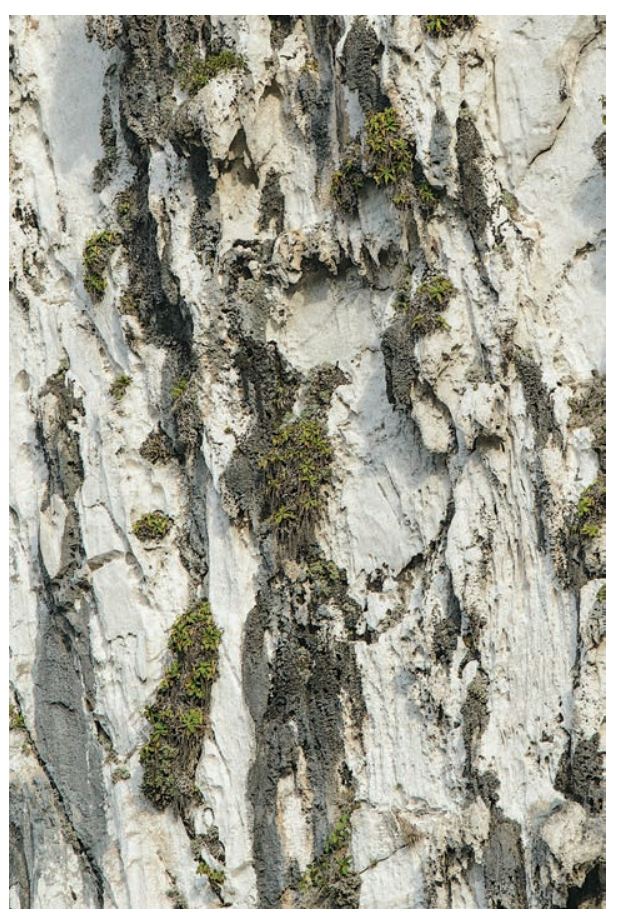

Figure 2: Plants of Nepenthes campanulata growing on the limestone cliff near the entrance of Deer Cave in Gunung Mulu National Park, Sarawak. lation of N. campanulata in Gunung Mulu National Park in Sarawak. As with the type locality, the plants were found to be growing on steep limestone cliffs (Fig. 2). Remarkably, the distance between the Sarawak population and the type locality was over $400 \mathrm{~km}$, with no obvious sites in between that could feasibly be colonized by $N$. campanulata. In 1998, voucher specimens were obtained from the Mulu site and deposited in the Kuching Herbarium (Borneo, Sarawak, Taman Negara Mulu, Batu Pajing, C. Lee S 87440 (SAR); C. Lee $S 87441$ (SAR)). Subsequent expeditions to Gunung Mulu National Park by C. Lee revealed that $N$. campanulata grows on several sheer limestone cliffs there, but nowhere easily accessible, with all plants growing between 100-300 $\mathrm{m}$ above sea level.

Within this habitat, N. campanulata is apparently quite specialized, and has been observed to grow only on sections of the cliff, which are rarely exposed to rain. These sites are easily distinguished by the white color and relatively smooth surface of the rock as opposed to a gray and often sharply eroded surface. Such zones remain dry either due to the overhanging angle of the cliff or the fact that rain predominantly blows from a direction which does not often strike the vertical face. Plants of $N$. campanulata typically grow with their roots embedded within spongy, often moist, tufa formations, and therefore must derive much of their water from that which seeps through the limestone.

Although $N$. campanulata has been rediscovered and its habit and habitat observed through binoculars and telephoto lenses, many aspects of its natural history have yet to be documented, because of the extreme challenges associated with physically reaching the plants on the high, vertical cliffs 


\begin{tabular}{|l|c|c|}
\hline \multicolumn{1}{|c|}{ Table 1. Average dimensions of Nepenthes campanulata pitchers. } \\
\hline Pitcher characteristic & Mean & $\begin{array}{c}\text { Standard } \\
\text { deviation }\end{array}$ \\
\hline Capacity (ml) & 24.06 & 11.77 \\
\hline Height (mm) & 9.31 & 1.80 \\
\hline Orifice diameter (front to rear) (mm) & 3.68 & 0.94 \\
\hline Orifice diameter (side to side) (mm) & 4.19 & 0.86 \\
\hline Lid length (mm) & 3.44 & 0.80 \\
\hline Lid width (mm) & 2.92 & 0.57 \\
\hline Hip position (distance from base to hip) (mm) & 3.74 & 0.61 \\
\hline Hip diameter (front to rear) (mm) & 2.37 & 0.46 \\
\hline Hip diameter (side to side) (mm) & 2.44 & 0.51 \\
\hline
\end{tabular}

on which they grow. For several years, it seemed that the logistical challenges to studying this plant in the wild could never be overcome, but in 2011, we had a unique opportunity to study Nepenthes campanulata in its natural habitat.

During filming for a television documentary, a film crew managed to abseil down the cliff above Deer Cave to film millions of free-tailed bats emerging from the cave at sunset. Several plants of $N$. campanulata grow on this cliff face, and as one of us (CL) also has the necessary skills and experience to abseil down this cliff, we managed to obtain permission to visit these plants and collect the contents of some pitchers, so that we could learn more about what sorts of insects $N$. campanulata traps, and what sorts of animals live in its pitcher fluid.

In addition, during a recent field trip to Palawan in the southern Philippines, we observed plants growing on limestone cliffs that we identified as $N$. campanulata. This represents a remarkable extension to the geographical range for this species, and gives us cause to reconsider the phytogeographic relationships between Borneo and Palawan with regards to the evolution and diversification of Nepenthes.

\section{Methods}

The habitat of $N$. campanulata is virtually inaccessible to humans. Aside from a small number of stray plants, the majority of plants grow approximately $200 \mathrm{~m}$ above the ground on sheer limestone cliffs above the entrance to Deer Cave in Gunung Mulu National Park. The only way to reach them is to abseil down to them from the top of the cliff, some $50 \mathrm{~m}$ above the plants. The undulating surface of the rock, along with sharp ridges and shelves, makes this a perilous activity. To survey the plants in their natural habitat, rope lines were anchored near the top of the cliff and Ch'ien abseiled down to the plants (Front Cover). Due to the slightly overhanging slope, it was necessary to use multiple anchor points down the cliff face in order to stay in close proximity with the rock. After surveying the plants and obtaining prey samples, Ch'ien ascended the fixed lines back to the top of the cliff.

A total of $17 \mathrm{~N}$. campanulata pitchers were observed, measured, and their contents analyzed using a Nikon Stereomicroscope. Identifiable prey were sorted, counted and identified to Order. Infaunal organisms were identified to genus (or species) where possible. The food web diagram was drawn in accordance with the methods of Clarke \& Kitching (1993). Pitcher dimensions were measured to the nearest mm, using the methods of Chin et al. (2010). 
Field work was conducted in accordance with Sarawak Forestry Permit Number 22/2011. Permission to abseil down the cliff face above Deer Cave was granted by the management of Gunung Mulu National Park.

\section{Results \& Discussion}

\section{Pitcher dimensions}

The pitchers of $N$. campanulata are comparatively small (Table 1), with a height similar to that of $N$. gracilis pitchers (Clarke \& Kitching 1993). However, the average ( \pm 1 S.E.) capacity of $N$. campanulata pitchers appears to be somewhat greater than $N$. gracilis $(24.06 \pm 2.68 \mathrm{ml}$ versus $14.40 \pm 1.17 \mathrm{ml}(n=20))$, due to the bell-shaped structure of $N$. campanulata. The waxy zone of $N$. campanulata pitchers extends from the orifice down to the hip, which is located approximately one third of the way up from the base. The position of the hip, coupled with the narrow dimensions of the pitcher in the lower third, strongly constrains the volume of fluid that the pitchers can accommodate. Although we were unable to accurately measure pitcher fluid volumes, these appear to be consistently less than $5 \mathrm{ml}$.

\section{Prey capture}

$N$. campanulata traps mostly small flies and ants, along with the occasional beetle, cricket, or moth (Fig. 3). This prey-capture profile is typical for a species with small, yellow pitchers that are produced at or above canopy level (Moran 1996; Bonhomme et al. 2011). However, it is highly atypical for a species that has a reduced peristome and well-developed waxy zone. The small peristome/well-developed waxy zone character combination has been referred to in recent ecological studies as "dry type". The pitchers of most Nepenthes species can be divided into two groups, called "wet type" and "dry type" (Bauer et al. 2012; Moran et al. 2013). Wet type pitchers tend to have a broad peristome and a reduced (or no) waxy zone. The peristome relies on moisture to function, and so species with "wet type" pitchers are confined to habitats that are almost permanently moist. By contrast, dry type pitchers have narrower peristomes and welldeveloped waxy zones. While the peristomes of dry type pitchers are less effective than those of wet type ones, the waxy zone remains effective even if the weather is dry. Furthermore, the wax crystals are better at retaining water than glandular surfaces, so dry type pitchers are more efficient in places where occasional, short term water deficiencies occur.

One thing that is intriguing about the prey caught by $N$. campanulata pitchers is that dry type pitchers are thought to be more effective

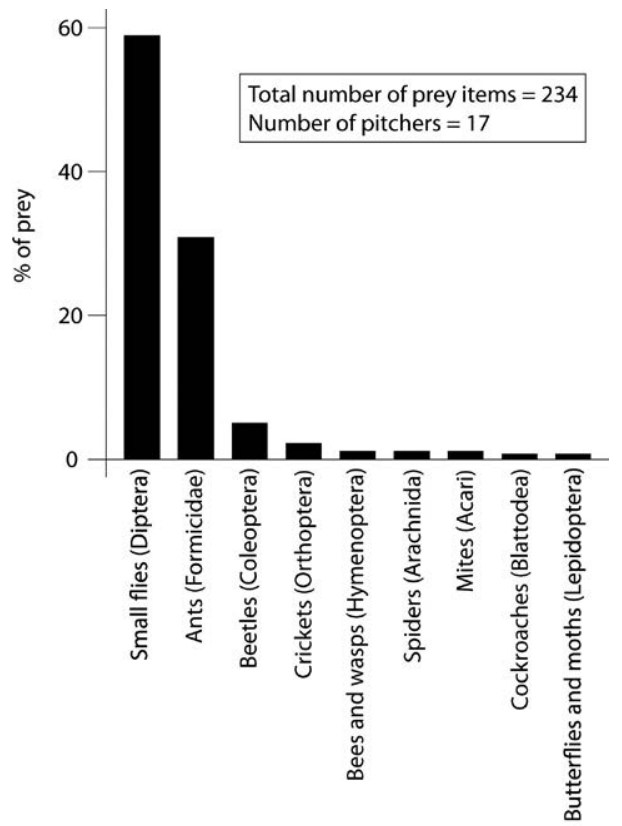

Prey Taxon

Figure 3: Histogram showing the proportional composition of arthropod prey taxa in Nepenthes campanulata pitchers. 
at trapping crawling prey, such as ants, and less effective at trapping flying prey, such as small flies (Bonhomme et al. 2011; Bauer et al. 2012; Moran et al. 2013). In this respect, our findings for $N$. campanulata pitchers are counter-intuitive and suggest that the dry-type pitcher format may also be highly effective at trapping flying prey. Moran et al. (2013) contend that the geographical distribution of trap types is governed solely by climate. Our findings support this assertion - most likely, the structure of $N$. campanulata pitchers reflects the highly specialized environment that $N$. campanulata occurs in, rather than specializations to target any specific type of insect prey.

It should be noted that our sample size is small, and our observations were based on a single sampling event, so there is potential for error in our findings and interpretations. That said, similar sample sizes have been used in other surveys of prey capture by Nepenthes and we feel that our results are likely to be representative, at least as far as rates of capture of Diptera and Formicidae are concerned. While there is a patent need for further, more detailed observations of prey capture by $N$. campanulata pitchers, the logistical challenges to doing this are extreme, and at present, there is little chance of these being overcome.

\section{Invertebrate fauna}

With only three species, the metazoan infauna of $N$. campanulata pitchers is one of the simplest recorded to date (Fig. 4) (Beaver 1985). Larvae of the mosquito, Tripteroides nepenthis, feed on the remains of captured insects, breaking down the carcasses and increasing the rate of digestion of prey. This species is a common inhabitant of lowland Nepenthes pitchers in open, disturbed habitats throughout Borneo, as are mites of the genus Zwickea. Somewhat surprisingly, we found that $N$. campanulata pitchers are also colonized by a species of Toxorhynchites, whose larvae are predators, feeding on the larvae of other mosquitoes and midges. Although the pitchers of several Nepenthes species from Borneo are colonized by Toxorhynchites, these larvae are generally found only in pitchers of Nepenthes species that have a rich infaunal community that contains several other mosquito and midge species. It remains to be seen whether Toxorhynchites is a regular colonist of $N$. campanulata pitchers, or whether it is an "accidental" colonist - with gravid females occasionally laying their eggs in $N$. campanulata pitchers, rather than larger congeners from nearby habitats, such as $N$. faizaliana, $N$. reinwardtiana, $N$. ampullaria, and $N$. bicalcarata.

Of the 17 pitchers we examined, nine had no metazoan infauna and a further two were colonized only by Zwickea sp. mites. Compared to other lowland Nepenthes species from nearby Brunei, this is an extremely low rate of pitcher colonization (Clarke \& Kitching 1993) and is similar to pitchers from sites that are the most marginal for infaunal organisms. This result suggests that the environment in which $N$. campanulata grows is extremely challenging for invertebrate larvae, and that only the most resilient species are able to colonize and persist in them.

\section{The geographical range of $N$. campanulata}

$N$. campanulata pitchers represent an extreme development of the dry type pitcher format. The peristome is reduced to such an extent that it is barely visible, but the waxy zone is very highly developed. This makes the pitchers

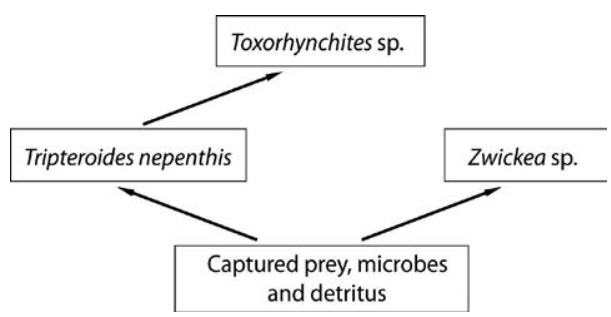

Figure 4: Summary metazoan food web for Nepenthes campanulata pitchers. Boxes represent metazoan species or sources of nutrition. Arrows show the directional transfer of energy/nutrients from one trophic level to the next. 
effective arthropod traps even when the weather is comparatively dry. Water loss from pitchers is minimized by reducing the digestive zone to a small area at the bottom of the pitcher, with a correspondingly small quantity of pitcher fluid. In other words, most of the surface area of the trap is devoted to capturing and retention of prey, whereas only a small part is devoted to the digestion of prey. The bell-shaped structure does not prevent rainfall from entering, but because the plants often grow beneath overhangs on the cliff face, they rarely receive large quantities of direct rainfall, so a bell-shaped pitcher with a small lid is not a disadvantage. These pitcher characteristics are instructive with regards to the niches that $N$. campanulata colonizes on limestone cliff faces. If $N$. campanulata grew on the most exposed parts of the cliff faces, the pitchers would often overflow whenever it rains, and the plants would be subjected to far greater water stress during dry spells. By growing beneath rocky shelves (whose surfaces stay moist longer than in exposed sites) the pitchers are protected from direct rainfall.

Few limestone escarpments in Borneo have cliffs with the type of shelves and overhangs that $N$. campanulata colonizes, which is why the recorded range of this species is not greater (Fig. 5). However, a wider geographical range within Borneo is possible, for two reasons: (1) large areas of karst terrain exist in eastern Borneo, and few of these have been explored in any detail for Nepenthes, and (2) N. campanulata only colonizes sites with a specific combination of features (see above). Cliffs that lack these features are devoid of $N$. campanulata plants, and probably always have been.

In July 2013, during an expedition to Palawan, we surveyed a number of sheer limestone cliffs that form part of the Saint Paul formation, which seemed to possess similar characteristics of the

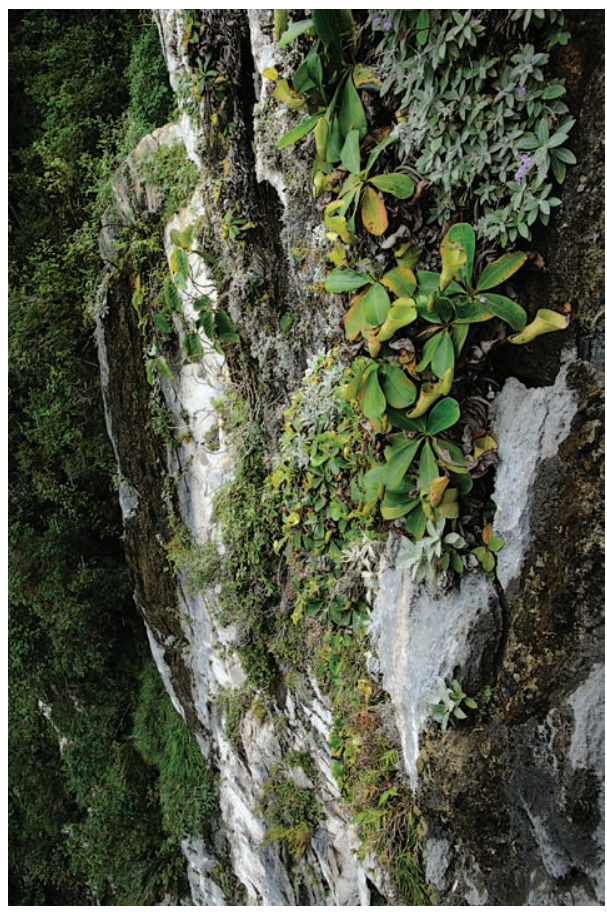

Figure 5: The extraordinary habitat of Nepenthes campanulata. Note the angle of the cliff face, which slopes inwards.

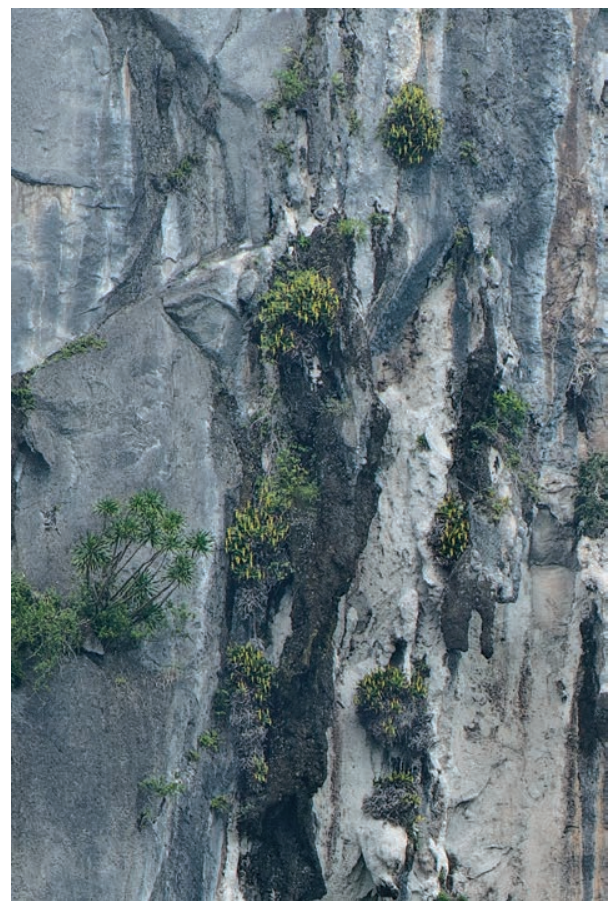

Figure 6: Plants that we identified as Nepenthes campanulata growing on a limestone cliff in the Saint Paul limestone region of Palawan. 
cliffs at Gunung Mulu National Park above Deer Cave (including being several hundred meters in height!). Scanning the cliffs with binoculars, we found a Nepenthes growing in precisely the same habitat niche as $N$. campanulata. Furthermore, the plant stature and growth habit, leaf shape, short tendrils, and bell-shaped pitchers corresponded to N. campanulata. Although we were unable to get close enough to the plants to make detailed observations of minor morphological characteristics (Fig. 6), we concluded that they represent $N$. campanulata. Of course, it is feasible that closer examination of these plants could show them to be an undescribed, closely related species, but we are comfortable with our identification, which allows the Palawan populations to be included in existing frameworks for conservation assessments (such as the IUCN Red List). We acknowledge that our identification of these populations is likely to cause debate, but we view that as a good thing and look forward to seeing our judgment put to test in the near future!

Acknowledgements: This research was funded by the School of Science, Monash University Sunway Campus, Selangor, Malaysia. Sarawak Forestry kindly granted us permission to conduct the research. Brian Clark at Gunung Mulu National Park gave permission for Ch'ien Lee to abseil down the cliff face above Deer Cave. Paris Wan provided vital technical assistance with the abseiling. Two anonymous referees kindly provided us with constructive feedback and comments about the manuscript.

\section{References}

Bauer, U., Clemente, C.J., Renner, T., and Federle, W. 2012. Form follows function: morphological diversification and alternative trapping strategies in carnivorous Nepenthes pitcher plants. Journal of Evolutionary Biology 25: 90-102.

Beaver, R.A. 1985. Geographical variation in food web structure in Nepenthes pitcher plants. Ecological Entomology 10: 241-248.

Bonhomme, V., Pelloux-Prayer, H., Jousselin, E., Forterre, Y., Labat, J-J., and Gaume, L. 2011. Slippery or sticky? Functional diversity in the trapping strategy of Nepenthes carnivorous plants. New Phytologist 191: 545-554.

Chin, L., Moran, J.A., and Clarke, C. 2010. Trap geometry in three giant Bornean Nepenthes species from Borneo is a function of tree shrew body size. New Phytologist 186: 461-470.

Clarke, C.M., and Kitching, R.L. 1993. The metazoan food webs of six Bornean Nepenthes species. Ecological Entomology 18: 7-16.

Kurata, S. 1973. Nepenthes from Borneo, Singapore and Sumatra. Gardens' Bulletin Singapore 26(2): 227-232.

Lee, C. 2004. New records and a new species of Nepenthes (Nepenthaceae) from Sarawak. Sandakania 15: 93-101.

Moran, J.A. 1996. Pitcher dimorphism, prey composition and the mechanism of prey attraction in the pitcher plant, Nepenthes rafflesiana in Borneo. Journal of Ecology 84: 515-525.

Moran, J.A., Gray, L.K., Clarke, C., and Chin, L. 2013. Capture mechanism in Paleotropical pitcher plants (Nepenthaceae) is constrained by climate. Annals of Botany doi:10.1093/aob/mct 195 . 


\section{CARNIVOROUS PLANT NEWSLETTER}

Journal of the International Carnivorous Plant Society

Volume 43, No. 1

March 2014

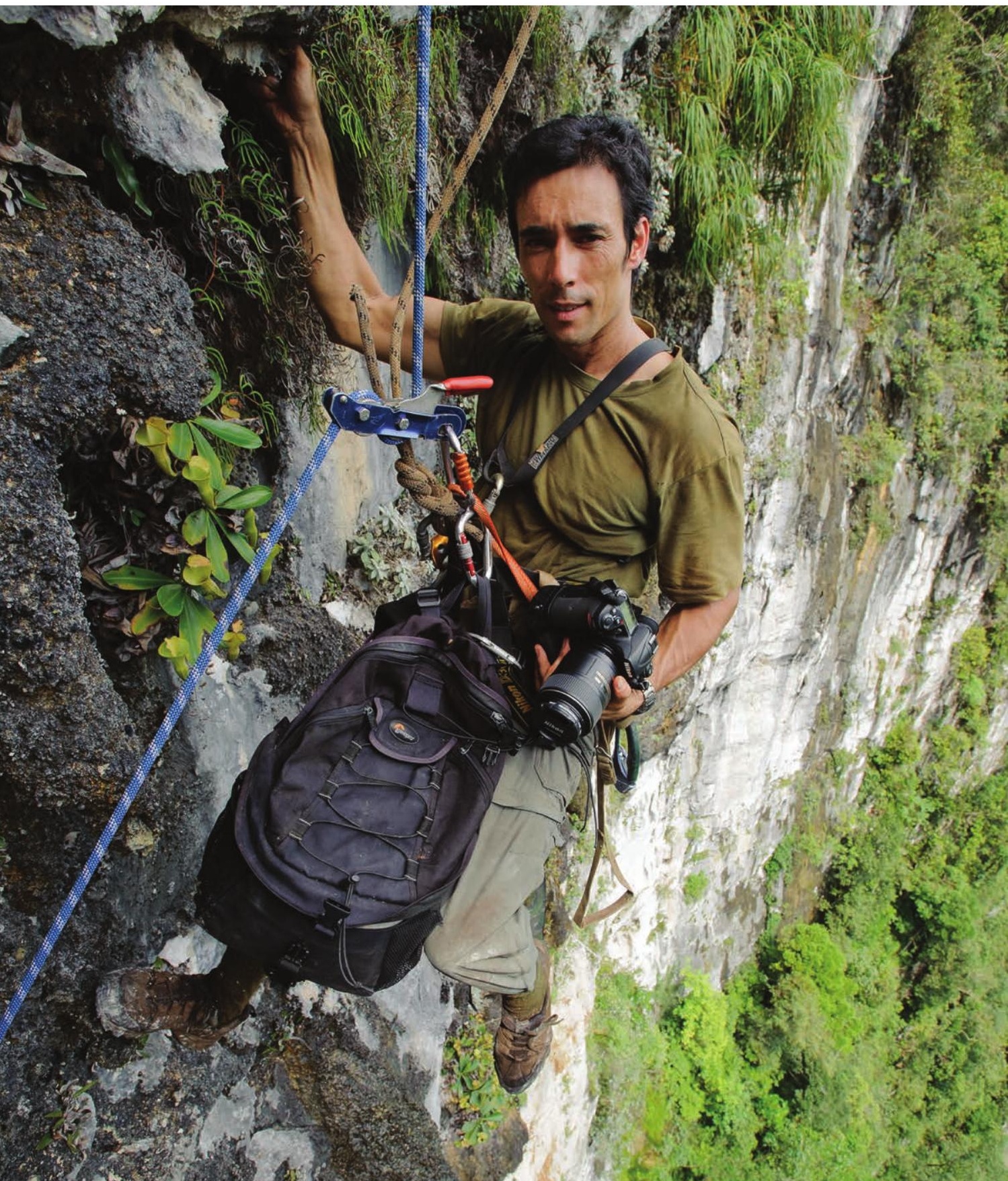




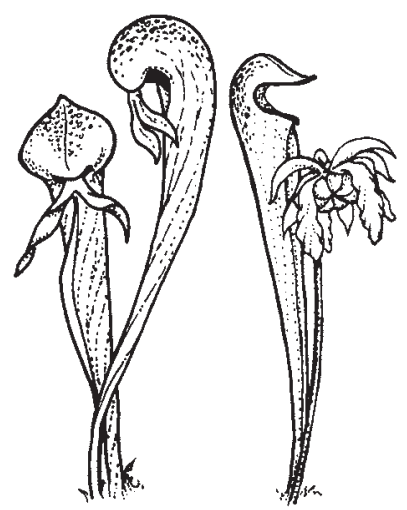

\section{CARNIVOROUS \\ PLANT \\ NEWSLETTER}

Journal of the International

Carnivorous Plant Society

www.carnivorousplants.org

\section{Volume 43, Number 1 March 2014}

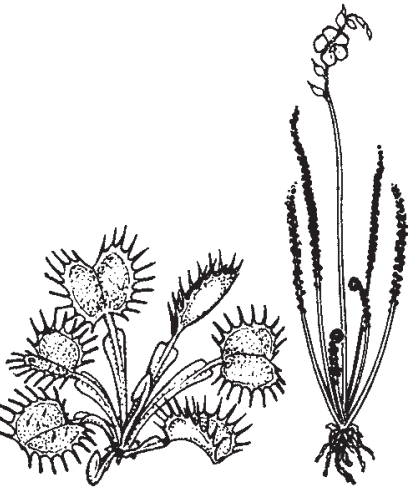

Front Cover: Ch'ien Lee in the habitat of Nepenthes campanulata, suspended approximately $200 \mathrm{~m}$ above the ground, on the rock face above Deer Cave in Gunung Mulu National Park, Sarawak. Ch'ien removed his safety helmet to pose for this photograph. Article on page 7.

Back Cover: Geoff Wong at the Bay Area Carnivorous Plant Society Show and Sale June 15, 2013. Geoff was talking about the Utricularia quelchii that he donated to the auction. Photo by Jeremiah Harris. Article on page 4.

Carnivorous Plant Newsletter is dedicated to spreading knowledge and news related to carnivorous plants. Reader contributions are essential for this mission to be successful. Do not hesitate to contact the editors with information about your plants, conservation projects, field trips, or noteworthy events. Advertisers should contact the editors. Views expressed in this publication are those of the authors, not the editorial staff.

All correspondence regarding dues, address changes and missing issues should be sent to the Membership Coordinator at the ICPS. Do not send such correspondence to the editors. Checks for subscriptions should be made to the ICPS in US funds. Dues for 2014 are \$35 for the first year of membership; renewals are \$30 per year.

International Carnivorous Plant Society, Inc.

2121 N. California Blvd., Suite 290

Walnut Creek, CA 94596-7351, USA

icps@carnivorousplants.org

President

Vice President

Secretary/Treasurer

Board Member

Board Member

Board Member

Board Member

Administrator

Seed Bank Manager

CPN Editors

Managing Editor

Editor

Editor

Science Editor

Science Editor
Michael Baldwin, michael@carnivorousplants.org

Marcel van den Broek, marcel@carnivorousplants.org

Richard Myers, richard@carnivorousplants.org

Greg Bourke, Conservation Director, greg@carnivorousplants.org

Richard Nunn, richardnunn@carnivorousplants.org

Jan Schlauer, jan@carnivorousplants.org

Bob Ziemer, bob@carnivorousplants.org

Cindy Slezak, cindy@carnivorousplants.org

John Brittnacher, john@carnivorousplants.org

editor@carnivorousplants.org

Bob Ziemer

Barry Rice

Djoni Crawford

Fernando Rivadavia

Jan Schlauer

Date of effective publication of the December 2013 issue of Carnivorous Plant Newsletter: 2 December 2013.

The ICPS is the International Cultivar Registration Authority (ICRA) for the names of cultivated carnivorous plants according to the International Code of Nomenclature for Cultivated Plants. Send relevant correspondence to the ICPS, Inc.

Carnivorous Plant Newsletter is published quarterly in March, June, September, and December by the ICPS, Inc., 2121 N. California Blvd., Suite 290, Walnut Creek, CA 94596, USA. Periodicals postage paid at Richmond, CA and additional mailing offices. Postmaster: Send address changes to ICPS, Inc., 2121 N. California Blvd., Suite 290, Walnut Creek, CA 94596, USA. Printed by Allen Press, Inc., 810 E. 10th Street, Lawrence, KS 66044. Logo and masthead art: Paul Milauskas. (C) 2014 Carnivorous Plant Newsletter. All rights reserved. ISSN \#0190-9215 